\title{
OCUPAR A PALAVRA: ENSINO E PESQUISA DE LITERATURA NO BRASIL
}

HABITER LES MOTS: ENSEIGNEMENT DE LA LITTÉRATURE ET RECHERCHE AU BRÉSIL

Maraíza Labanca*

RESUMO: Este artigo aborda a experiência com a palavra literária nas 偆oes de ensino do Brasil, refletindo sobre sua suas possibilidades de transmissão e de pesquisa. Para isso, procura discutir os méodos dominantes, os problemas que esses métodos acarretam, bem como apontar saídas que possam reaproximar a literatura de uma rática, de um fazer. Discutem-se, ainda, a potência da "anti-institudessa matéria, que comporta um "regime discursivo de exceça”, e o desenvolvimento de um "pensamento poético", que não deve ser preexistente à leitura.

PALAVRAS-CHAVE: Ensino; pesquisa; experiência; prática; pensamento poético.
* maraizalabanca@gmail.com

Doutora pelo Programa de Pós-graduação (POS-LIT) da Faculdade de Letras da UFMG (FALE-UFMG).

RÉSUMÉ: Ce texte discute l'expérience avec le «mot littéraire» dans les

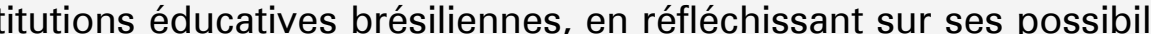
tés de transmission et de recherche. Pour cela, il discute des méthodes dominantes, des problèmes que ces méthodes impliquent, et indique des façons de reconnecter la littérature à une pratique, à un "faire». Le pouvoir de "l'anti-institutionnalité» de la littérature, qui comprend un «régime discursif d'exception», et le développement d'une «pensée poétiquen, qui ne devrait pas préexister à la lecture, sont également discutés.

MOTS CLÉS: Enseignement; recherche; expérience; pratique; pensée poétique. 
1. PESSANHA. A exclusão transfigurada. In: Instabilidade perpétua, p. 56

2. PESSNHA. A exclusão transfigurada. In: Instabilidade perpétua, p. 58-59.
JP viu-se obrigado a simular uma competência dentro do elemento escolar, elemento cujo nome é abstração..

O problema é que o progresso na abstração, o grau de distanciamento em relação ao sentir ressoante do corpo na proximidade das coisas concretas, constitui o chamado do mundo e o chamado escolar. [...]

E é um tal domínio que a escola pede de um menino!

[...] O menino que queria parar o carro do pai para pegar nas mãos a linha do trópico de Capricórnio'.

Mas a língua-viva, a língua concreta estava interditada em todos os lugares e JP atravessou todo o período escolar fazendo ginásticas verbais e roubando relatos. Prosseguia picotando e soletrando, pois assistia cada palavra, cada "produção linguística” com a angústia de saber-se fraudulento.

Tomamos a força do testemunho do escritor Juliano Garcia Pessanha para problematizar a posição da palavra literária nas instituições de ensino do Brasil, o que implica refletir tanto sobre a sua transmissão em sala de aula quanto sobre a sua pesquisa. Mais do que refletir, questionar estratégias e métodos dominantes de transmissão implica propor modos de abordagem que abalem a distância entre a escrita, a leitura e a teoria. Para isso, seria preciso perguntarmo-nos, antes, a que se atribui a debilidade da literatura na educação, cujo espaço é cada vez mais exíguo.
Juliano Pessanha parece indicar que o problema do ensino vincula-se à conversão da palavra literária em saberes e competências consoantes com o espírito produtivista que se apossa da sala de aula. Disso decorre a reprodução de um regime de leitura dado de antemão, cuja premissa seria o domínio do texto, de seu contexto, de sua estrutura e de sua língua. Ao limar os efeitos de leitura sobre quem lê, a distância está posta; e a palavra literária, a "língua-viva" ou a "língua concreta", segundo nomeia o escritor, permanece interditada.

Roland Barthes, em conferência pronunciada no colóquio Ensino da Literatura, em 1969, já anunciava que, muitas vezes, o que resta do ensino dessa disciplina, para os alunos, são objetos mortos: os estilos de época, os gêneros, os séculos. ${ }^{3}$ Nesse momento, Barthes problematizava a redução da transmissão da literatura à sua historiografia, baseada em "individuações estereotipadas" dos autores, das obras e das épocas. Recorria-se - e ainda se recorre - a uma explicação do texto a partir de predicados que ora se combinam ora se diferenciam, determinando, assim, pares de oposição que, didaticamente, evidenciam os paradigmas capazes de identificar as escolas literárias. Com isso, ficava estabelecida uma estrutura elementar e taxológica, como Romantismo vs. Realismo.

Contudo, conforme assinala Paulo de Andrade, outros problemas incidem sobre o ensino de literatura no Brasil, como a
3. Cf. BARTHES. Reflexões a respeito de um manual. In: O rumor da língua, p. 43.

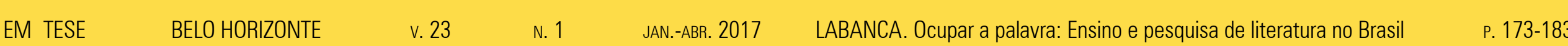


4. Cf. ANDRADE. “Tenho um desejo imenso de alterar a comunidade que vivo": Literatura, política e escola segundo Bartolomeu Campos de Queirós, p. 3.

5. Cf. LOPES. A paradoxalidade do ensino da literatura. In: Literatura defesa do atrito, p. 87-99.

6. REYES. Ler e brincar, tecer e cantar. In: Literatura, escrita e educação, p. 21 sua imbricação com o da língua portuguesa: o estudo de suas normas e de suas variações, o estudo e a classificação dos gêneros textuais. ${ }^{4}$ Tal fato, esclarece esse autor, confere à literatura um lugar ilustrativo e uma posição acessória no ensino, acarretando, inclusive, perda de espaço nos currículos escolares. Privilegiam-se, nesse caso, aspectos linguísticos durante a leitura, o que faz com que os textos literários sejam tomados como qualquer outro, seja ele publicitário, jornalístico ou científico.

Silvina Rodrigues Lopes, por sua vez, avalia que, após a década de 60 , teria ocorrido a tecnocratização do ensino da literatura. ${ }^{5}$ Para a autora, a cobrança por uma "eficácia técnica", durante a leitura dos textos, advinha da incidência do estruturalismo nas escolas. O texto passou a ser, a partir desse momento, circunscrito a uma forma fechada e acabada, e sua potência criadora era, com isso, aniquilada. No Brasil, a ênfase dada a essa "eficácia técnica" tem ainda, como motivação, sobretudo nas salas de aula de Ensino Médio, o treinamento para processos seletivos de ingresso às universidades, em especial o ENEM. Tanto nesse caso como no outro, o que se evidencia é o caráter utilitário dado à leitura, conformada, portanto, a uma Ordem, a uma "verdade", isto é, a um sentido recomendável, segundo ditam as instâncias de poder.

As estratégias, em ambos os casos, visam a um consenso "que obriga todos a sublinharem a mesma coisa em um mesmo parágrafo" ${ }^{6} \mathrm{de}$ um texto, extraindo-lhe as mesmas "ideias principais". O texto é, assim, na sua multiplicidade, limitado a uma realidade estável e a um mesmo ponto de vista. Essa abordagem uniformizante, que veicula um sentido único, exclui a possibilidade de tomar a literatura como uma "experiência específica”. 7 A exigência por uma correção e por uma adequação faz, então, definhar a palavra literária, reduzindo-a a "ginásticas verbais" e a um automatismo que desconsidera o modo singular de um texto literário fazer sentido: "a peculiar relação que ele instaura a cada vez que é lido".

O historicismo, a imbricação com o ensino da língua portuguesa, a ênfase na eficácia técnica, a uniformização da leitura e o utilitarismo afastaram a literatura do campo das artes, contrariando, segundo esclarece Paulo de Andrade, até mesmo o que propõe o MEC nas "Orientações Curriculares para o Ensino Médio”. Nesse documento, conforme indica Andrade, afirma-se uma certa autonomização da literatura, isto é, aposta-se na especificidade de sua linguagem. Encontramos, inclusive, em suas linhas, a seguinte formulação: “a literatura é uma arte”. Contudo, professores e equipe pedagógica de escolas - e mesmo dos cursos de Letras, em que professores são formados - parecem ignorar as recomendações desse instrumento de apoio oferecido pelo MEC.

Limitar o estudo da literatura a competências e teorias preexistentes retira-lhe a dimensão incitante, só ela capaz de alargar o campo do sensível e do pensável. Salvaguardar
7. ANDRADE. "Tenho um desejo imenso de alterar a comunidade que vivo": Literatura, política e escola segundo Bartolome Campos de Queirós, p. 3.

8. LOPES. Poesia e ideologia. In: Literatura, defesa do atrito, p. 71

$\begin{array}{lllll}\text { EM TESE } & \text { BELO HORIZONTE } & \text { v. } 23 & \text { N. } 1 & \text { JAN.-ABr. } 2017 \\ \text { LABANCA. Ocupar a palavra: Ensino e pesquisa de literatura no Brasil } & \text { P. 173-183 }\end{array}$ 
9. LOPES. A paradoxalidade do ensino da literatura. In: Literatura, defesa do atrito, p. 93-94.

10. BARTHES. Reflexões a respeito de um manual. In: O rumor da língua, p. 50 a literatura, ao contrário, significa, de acordo com Silvina Rodrigues Lopes, não sujeitá-la a uma autoridade (autor, sentido) nem às tiranias da técnica e do contexto. Isso exige, pois, "o reforço da problematização ao nível do ensino superior, de modo a consolidar um tipo de relação que assenta bases comuns em todos os níveis de ensino, embora assuma aspectos diferentes". ${ }^{9}$ Reforcemos, pois, essa problematização ao nível do ensino superior, onde se formam nossos professores, lembrando que afastar a literatura do campo das artes implica ratificar a antinomia entre a literatura como ensino e a literatura como prática. Essa antinomia, escreve Barthes, "é grave, porque se prende ao problema da transmissão do saber". ${ }^{10}$

Se tomarmos a Literatura como arte, e é por isso que seu ensino se justifica (ao menos aqui), por que ela deveria permanecer nesse casamento monogâmico e submisso com a língua, e não partir para relações mais abertas, com as outras artes? Quero dizer bem literalmente: por que a Literatura não é ensinada como arte? Vejam bem, não estou pensando nisso como uma premissa abstrata; interessa-me sobretudo pensar as mudanças estruturais e as novas metodologias que seriam mais pertinentes a esse novo objeto: a literatura como arte, já que aquele que conhecemos é apenas a literatura como gênero textual ou como história, e isso também nas universidades.

Penso que essas questões nos exigem o movimento de rever o nosso objeto. O que é a literatura? Ou: o que queremos da literatura? E, para ser mais específico, o que se ensina na disciplina literária? A célebre "leitura crítica"? Estamos, com isso atendendo as especificidades desse objeto difuso, que, lembremos, aciona "um conhecimento que objetivamente não se pode mensurar", como admite ainda o documento do MEC? O que fazemos nós da literatura?

Para responder a essas perguntas, talvez devamos começar por admitir que nunca ensinamos literatura. Não a literatura arte. Ensinamos, muito provavelmente, discursos sobre a literatura: o histórico, o teórico, o técnico, o linguístico, o crítico... ${ }^{11}$

Se apenas contornamos a literatura com discursos que nela se põem a girar, deixamos de tocar o que nela excede esses discursos, aquilo que se abre à dimensão do incognoscível. Não se trata, no entanto, de excluir esses discursos das salas de aula, mas de reaver, para o ensino de literatura, seu "poder de resistência". ${ }^{12}$ Segundo Paulo de Andrade, em última análise, a literatura resiste "a certa ideia de saber, a qual estão ligadas as noções mais correntes de legibilidade, entendimento e sentido [...]"13. Entretanto, ao perder terreno para os especialistas, o acesso a esse setor da experiência é bloqueado, sem que se encontre um dizer afastado da "dizibilidade adestrada" ${ }^{14}$ que ora vigora nas salas de aula.

De acordo com o escritor Juliano Pessanha, "quando o processo de objetivação e de explicação submete e domina cada
11. ANDRADE. "Tenho um desejo imenso de alterar a comunidade que vivo": Literatura, política que vivo": Literatura, politica Campos de Queirós, p. 5

12. ANDRADE. "Tenho um desejo imenso de alterar a comunidade que vivo": Literatura, política e escola segundo Bartolome Campos de Queirós, p. 4.

13. ANDRADE. "Tenho um desejo imenso de alterar a comunidad que vivo": Literatura, política Campos de Queirós, p. 4.

14. PESSANHA. Em louvor ao júbilo. In: Instabilidade perpétua, p. 72

$\begin{array}{lllll}\text { EM TESE } & \text { BELO HORIZONTE } & \text { v. } 23 & \text { N. } 1 & \text { JAN.-ABr. } 2017 \\ \text { LABANCA. Ocupar a palavra: Ensino e pesquisa de literatura no Brasil } & \text { P. 173-183 }\end{array}$


15. PESSANHA. Como fracassar em Literatura. Pausa, p. 16.

16. PISSOLATI apud LABANCA. a mais: palavra súbita, cheia $\mathrm{d}$ sargaços ou afetiva, p. 2

17. ANDRADE. “Tenho um desejo imenso de alterar a comunidade que vivo": Literatura, polltica Campos de Queirós, p. 2.

18. LOPES. A literatura como experiência. In: Literatura, defes experiencia. In:
do atrito, p. 21. vez mais regiões da experiência, mais o dizer migra para o especialista e mais diminui o espaço da província literária". ${ }^{15}$ Nos próprios cursos de Letras, tanto no âmbito da graduação como da pós-graduação, segundo avalia Tiago Pissolati, “faz-se um 'convite' elegantemente coercitivo à leitura, mas acompanhado de uma mordaça para qualquer ímpeto mais atrevido de escritura". ${ }^{16}$

Para compreender de outra maneira a experiência literária, seria preciso, portanto, segundo Paulo de Andrade, não só "repensarmos nossas práticas de ensino na contemporaneidade mas talvez, e sobretudo, reavaliarmos o lugar instituído da literatura no espaço escolar". ${ }^{17} \mathrm{O}$ que seria criar um novo espaço para a literatura dentro das instituições de ensino? Para aproximá-la mais ao campo das artes que da linguística ou da ciências humanas, é necessário assumir a "anti-instucionalidade"18 da literatura, o que, por sua vez, pode dar origem a um impasse insolúvel - como dar lugar àquilo que é anti-institucional dentro mesmo da instituição de ensino? - ou pode criar espaços mais potentes dentro das escolas e das universidades, sem deixar de lhes pôr em causa. Nesse caso, a literatura, não mais como instrumento pedagógico, é o que permitiria ao aluno a "tomada da palavra".

No campo do ensino da literatura, importa por conseguinte desenvolver a todos os níveis a crítica de um ideal de comunicabilidade absoluta e abandonar a busca de técnicas de ensino, ou de pedagogias, orientadas para a obtenção da facilidade na transmissão de conteúdos. Note-se que aquele ideal se associa a um exagero do pedagogismo (o ensino que se liberta da matéria a ensinar) contra cujos efeitos perniciosos alertava já em 1960 Hannah Arendt [Arendt, 1972: 234], a propósito do ensino nos EUA. Neste sentido, há que ter em conta que o ensino da literatura exige um tempo próprio, que nada tem a ver com a velocidade de circulação de informações [...]. ${ }^{19}$

No ensino de música, do teatro e de outras artes, seja nas escolas ou nas universidades, "os alunos são implicados numa prática da própria arte em si (sem que isso exclua necessariamente também o estudo da história da arte e de suas formas de linguagem) [...]. Por que não nos colocarmos (nós, junto aos alunos) numa relação de proximidade, de intimidade com a linguagem [...]?"20. Parece-nos que é essa relação de proximidade, de intimidade com a linguagem, o que reclamava Juliano Pessanha no fragmento transcrito ao início deste artigo. Reduzir a distância entre a literatura e os alunos é permitir que eles tomem a palavra para si, é permitir que eles encontrem "o fio de sua própria escritura", como uma "afirmação de dissemelhança", ${ }^{21}$ uma maneira singular de participar do mundo, experimentando-a, a literatura, menos como um sistema já dado de textos canônicos, mas como sujeitos escritores e leitores, ${ }^{22}$ podendo, assim, atuar de fato na
19. LOPES. A paradoxalidade do ensino da literatura. In: Literatura, defesa do atrito, p. 98.

20. ANDRADE. "Tenho um desejo imenso de alterar a comunidade que vivo": Literatura, política que vivo": Literatura, politica Campos de Queirós, p. 7

21. LOPES. Defesa do atrito. In: Literatura, defesa do atrito, p. 139

22. Cf. sobre isso também ANDRADE. "Tenho um desejo imenso de alterar a comunidade que vivo" Literatura, política e escola segundo Bartolomeu Campos de Queirós.

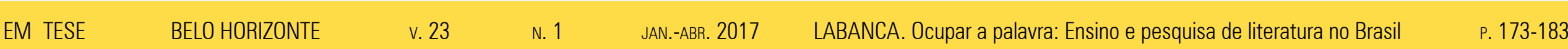


23. PISSOLATI apud LABANCA. a mais: palavra súbita, cheia de sargaços ou afetiva, p. 2 .

24. As oficinas de escrita literária, em sua maioria, ficaram restritas, o Brasil, a eventos culturais vez que não ganham espaco nas universidades e nas instituiç̃os de ensino básico. Entretanto, na França por exemplo, já há alguns anos é por exemplo, ja ha alguns anos è acadêmico, um espaço - ainda que compartimentalizado - voltado para a prática da escrita. Em Paris VIII - Saint-Denis, foi criado, em 2013-1014, um Master de Création littéraire, cujos desdobramentos já têm sido avaliados como positivos pelos alunos e profissionais da área. (Sobre isso, cf. LEBARD. A l'école des futurs ecrivains. Le monde. Jan. 2017)

25. A escritora e professora da Faculdade de Letras da UFMG Lucia Castello Branco, buscando verificar os pontos de tangência entre as linguagens poética $e$ psicótica, introduziu, 26 anos atrás, as Práticas da Letra em instituições psiquiátricas de Belo Horizonte. Apostando no ponto de radicalidade da letra, sua experiência foi transmitida e ampliada, depois, para outros praticantes, passando a englobar "Prática da letra" , em vez dom "Oficina da letra", em vez de diferença que aqui também nos interessa pensar: A Prática da Letra não visa a um fim não propõe divertimento, "arrisca-se, no entanto, a almejar um começo em que um ponto - um pingo - é letra que não se lê, mas que - é letra que não se lê, mas que
nos permite, afinal, começar a nos permite, afinal, começar a
escrever". (Cf. BRANCO; OLIVEIRA et al. Práticas da letra, p. 361-381.)

linguagem; agir e "ser agido" por ela. "Ora, se encontrar o fio de sua própria escritura não é tentar conhecer o incognoscível da literatura, eu me pergunto o que, de fato, é conhecer literatura" ${ }^{23}$, complementa Tiago Pissolati em depoimento que nos foi enviado.

Refletir sobre essa possibilidade significa perguntarmo-nos por que, no Brasil, as oficinas de criação literária ${ }^{24}$, ou as "Práticas da letra", conforme cunhou Lucia Castello Branco a partir de sua experiência com pacientes de instituições psiquiátricas de Belo Horizonte ${ }^{25}$ concebendo efetivamente uma práxis, isto é, uma experiência concreta com a língua tendem a ocorrer predominantemente fora dos muros das escolas e das universidades.

Desacostumar o lugar do professor, do aluno e da própri instituição de ensino como um todo parece-nos uma saída possível ao lamento irremovível de um suposto "declínio da literatura" e ao desinteresse generalizado que a disciplina ganhou no mundo da produtividade. A poesia, como à margem do mundo das trocas, desonera-se das facilidades de comunicação, assume-se como desclassificada; o que quer dizer que algo na obra resiste à sua catalogação, que nada mais é que a circunscrição e o domínio de suas qualidades. Algo na obra empurra-a para fora da história, e isso o ensino não pode desconsiderar: impor-lhe um limite é ferir sua natureza. Por isso, parece-nos salutar devolver à literatura a sua força de

disrupção dos contextos e dos códigos aos quais apenas por hábito estaria amalgamada.

Talvez um autor como Peter Pál Pelbart dissesse, sobre esse tema, que preciso seria ocupar a literatura, como fizeram os secundaristas e universitários em escolas públicas de Ensino Médio e em universidades pelo Brasil no segundo semestre de 2016, sob o risco de se verem expropriados daqueles espaços. Ocupar a literatura, como se ocuparam as escolas, ${ }^{26}$ no sentido de se apropriar dela, dessacralizando-a e reinvestindo-a daquilo que o ensino sequestrou: um fazer. Ocupar a palavra, habitá-la e, ao mesmo tempo, desocupá-la daquilo que a esteriliza. Com isso, seu ensino nas escolas e nas universidades não deixaria mais como restos objetos mortos, mas uma "experiência radical com a linguagem" 27 que, eticamente, pode redimensionar o sujeito diante do mundo: "a incapacidade de ajustar-me ao mundo das medidas era, na verdade, a potência poética pedindo passagem para inaugurar um outro mundo e uma outra vida". ${ }^{28}$

Para Barthes, a ciência é o que se ensina. Mas sabemos que a literatura não pode ser ensinada como ciência, uma vez que seu objeto - o texto - esquiva-se, por todos os lados, de uma análise que prime exclusivamente pela objetividade. "A ciência se fala, a literatura se escreve". ${ }^{29}$ Ao mesmo tempo, pode-se dizer que o mundo da obra é capaz de reunir em si um conjunto de saberes (sociais, históricos, psicológicos etc.)
26. Cf. PELBART. Carta aberta aos secundaristas. São Paulo: n-1 edições, 2016.

27. ANDRADE. “Tenho um desejo imenso de alterar a comunidade que vivo": Literatura, política e escola segundo Bartolomeu Campos de Queirós, p. 9.

28. PESSANHA. A exclusão transfigurada. In: Instabilidade perpétua, p. 53.

29. BARTHES. Da ciência à literatura. In: O rumor da língua, p. 6. 
30. BARTHES. Da ciência à literatura. In: O rumor da língua, p. 5. que o campo das ciências fragmenta e compartimentaliza. Essa "grande unidade cosmogônica" professa, não obstante, de modo distinto, a linguagem que a constitui, assumindo-a não como instrumento transparente, em favor de um enunciado (como os resultados e as conclusões científicas). Os conteúdos, sejam eles quais foram, perdem, no texto literário, sua primazia: "Eticamente, é tão-somente pela travessia da linguagem que a literatura persegue o abalamento dos conceitos essenciais de nossa cultura [...]. Politicamente, é ao professar e ao ilustrar que nenhuma linguagem é inocente [...] que a literatura é revolucionária” ${ }^{30}$ Atentar para (e questionar) a prática dominante de abordagem dos textos, em que se percebe uma surdez em relação à linguagem, é, portanto, pôr em crise a própria linguagem bem como o discurso do Outro, o discurso do poder.

Um dos efeitos dessa reflexão é também repensar o lugar do pesquisador em literatura, que, por vezes, contaminado pelos procedimentos científicos que o rodeiam, já que a literatura não está alocada ao lado do campo das artes, procura também eludir a sua própria linguagem, afastando do centro de seu interesse a literatura como "a própria subversão da linguagem científica”. ${ }^{31}$ Em outras palavras, também na pesquisa em literatura, a literatura como prática (de leitura e de escrita) é afastada para a margem, a fim de se assegurar um trabalho com os atributos caros às ciências humanas: clareza, rigor, método, resultados, obediência às leis do raciocínio.
Importamos métodos disseminados nas ciências humanas sem nos perguntarmos se esses seriam os mais pertinentes no que diz respeito à abordagem da literatura. Esquecemonos, então, de inventar nossos próprios métodos. Ainda atrelados ao "imaginário do cientista", esquecemo-nos de ler um texto sem compartimentá-lo em saberes distintos, que negligenciam, enfim, aquilo que seria sua "irredutível inadequação", 32 como algo de informulado, que a nada adere. Irredutível inadequação, inclusive, em relação à crítica estabelecida.

Alcançar "a literatura não como 'objeto' de análise, mas como atividade de escritura", ${ }^{33}$ o que não significa recair na pura metalinguagem, parece, nesse momento, um caminho para se combater os usos e abusos de uma "linguagem escrava"34. É importante advertir, no entanto, que tomar a palavra no sentido que damos à expressão aqui, não se refere à prática de um "belo estilo", mas ao reencontro com "os problemas candentes de toda enunciação" ${ }^{35}$, em que se supõe um sujeito $^{36}$, abalando, com isso, a ilusão da objetividade. Não se trata de ceder a juízos de valor que, de novo, colocariam em risco a dimensão de uma "experiência literária", no sentido que foi dado à expressão por Maurice Blanchot. ${ }^{37}$ Não se trata, ainda, de (ensinar a) "escrever particularmente bem", 38 como bem notou o escritor e artista plástico Nuno Ramos ao mencionar a literatura que lhe interessava. Segundo Silvina Rodrigues Lopes, se o dizer da literatura se conforma a um
32. RAMOS. Ó, p. 172.

33. BARTHES. Da ciência à literatura. In: O rumor da língua, p. 8.

34. BARTHES. Da ciência à literatura. In: O rumor da língua, p. 8.

35. BARTHES. Da ciência à literatura. In: O rumor da língua, p. 8.

36. Tomamos aqui o sujeito como categoria distinta do indivíduo (psicológico, biográfico, social).

37. Cf. BLANCHOT. O espaço literário. Trad. Alvaro Cabral. Rio de Janeiro: Rocco, 2011.

38. RAMOS. Nuno Ramos. Jornal Rascunho, p. 7.

\begin{tabular}{|c|c|c|}
\hline & BELO HORIZONTE & v. 23 \\
\hline
\end{tabular}

\section{Teoria da literatura e Ensino de literatura}


39. LOPES. A literatura como experiência. In: Literatura, defesa do atrito, p. 28.

40. LOPES. Defesa do atrito. In Literatura, defesa do atrito, p. 138.

41. RAMOS. Nuno Ramos. Jornal Rascunho, p. 5.

42. No dicionário Houaiss, assim são arrolados os sentidos possíveis dessa palavra (rigor): 1 rijeza material, física, ausência de flexibilidade, de maleabilidade; rigidez, dureza, inflexibilidade, 2 grande severidade (de princípios, de moral etc.); 3 falta de tolerância; intransigência; 4 crueza, rudeza nas atitudes, no trato com os demais, falta de candura; aspereza; etc. sinônimos dureza, firmeza, inflexibilidade, intransigência, obstinação, rigidez, severidade; antônimos: brandura, clemência, delicadeza, lenidade. (C. HOUASS, VILLAR. Rigor. In: língua portuguesa.)

43. BARTHES. Escritores, intelectuais, professores. In: O rumor da língua p. 396. "bem-escrever", tornando-o aceitável para a cultura e para o mercado, conforma-se, igualmente, "às instâncias que se arrogam o poder de julgar em nome da Lei”. ${ }^{39}$

Não se trata, também, de ler bem. Nem mal. Trata-se de ler/escrever sem limar do texto os seus excessos, isto é, aquilo que nele é excedente à comunicação; ler/escrever considerando o que a palavra literária pode deixar, no mundo, como espaço vazio, não funcional, que passa através das grades do significado, sem se deixar absorver. Para isso, devemos admitir que, no poema, na literatura, "há uma fala que não fala de", ${ }^{40}$ rarefazendo os conteúdos, os enunciados e consistindo um "patrimônio excessivo", ${ }^{41}$ que é, por isso, a-patrimonial

Seria preciso, portanto, pensar em um outro tipo de rigor ao reavaliarmos nossos métodos - de ensino e de pesquisa Um rigor que não denote rigidez, como indica seu primeiro sentido dicionarizado, ${ }^{42}$ mas que aponte uma obstinação pelo seu sentido (o de rigor) lançado ao avesso, isto é, acolhendo a flexibilidade, a delicadeza e até a plasticidade das palavras. E Barthes quem lembra que o método é uma lei a sacrificar o desejo; quando tudo passa para o método, "nada mais resta para a escritura": "nada mais seguro para matar uma pesquisa e fazê-la juntar-se ao grande lixo dos trabalhos abandonados, nada mais seguro que o Método" ${ }^{43}$ Em outras palavras, não deve ser o método a fundar o texto, mas o texto a fundar um método. A leitura/a escrita, sem apoio que a preceda ou a determine, deve admitir uma certa deriva, o erro, por meio de um "gesto de abertura ao incontrolável". ${ }^{44}$

Se "o discurso científico arroga-se uma autoridade que a escritura deve precisamente contestar" ${ }^{\prime 5}$ - uma vez que ela traz consigo o discurso do desejo -, contestando, com isso, também o papel do professor e, por extensão, do pesquisador, tal contestação perturba, estremece a segurança do cientista; eis, então, seu caráter nocivo. Segundo Barthes, o que se descobre ou está por se descobrir nas ciências (seja no campo sociológico, psicológico, psiquiátrico etc), “a literatura sempre soube; a única diferença é que ela não o disse, escreveu", ${ }^{46}$ como se, de maneira derrisória e ao mesmo tempo séria, a escrita literária apresentasse um saber cujo lugar é distinto do positivismo burguês, despojando-se dos álibis tecnicistas e cobrando de nós, leitores e escritores em potencial, um pensamento poético.

Para Jacques Derrida, o pensamento poético, ou a poesia como pensamento, exige o encontro, em um texto, com o in traduzivel, quando as palavras são agitadas em sua realidade discursiva ${ }^{47}$ limitando, assim, a legibilidade corrente e a interpretação prescritiva. Se o teórico, "o médium da verdade", é, para Derrida, aquilo que se olha de uma certa distância, sem se tocar com o corpo, sem contágio, a poesia como pensamento, poderíamos dizer, faz-nos transitar da distância à proximidade, da proximidade à distância, numa travessia
44. LOPES. A literatura como experiência. In: Literatura, defes do atrito, p. 23.

45. BARTHES. Da ciência à literatura. In: O rumor da língua, p. 10.

46. BARTHES. Da ciência à literatura. In: O rumor da língua, p. 12.

47. Cf. DERRIDA. Pensar em não ver: escritos sobre a arte do visíve (1979-2004), p. 17-61.

$\begin{array}{lllll}\text { EM TESE } & \text { BELO HORIZONTE } & \text { V. } 23 & \text { N. } 1 & \text { JAN.-ABr. } 2017 \\ \text { LABANCA. Ocupar a palavra: Ensino e pesquisa de literatura no Brasil } & \text { P. 173-183 }\end{array}$


48. LOPES. Defesa do atrito. In: Literatura, defesa do atrito, p. 139.

49. Para Barthes, ao contrário do professor, o escritor é, como o louco e o matemático, aquele cuja "mensagem" não pode ser resumida - "o resumo é a denegação da escritura". (Cf. BARTHES. Escritores, intelectuais, professores. In: O rumor da língua p. 389.)

50. Cf. HEIDEGGER. O fim da filosofia e a tarefa do pensamento. In: Conferências e escritos filosóficos. São Paulo: Nova Cultural, 1999. que não ocorre sem contaminações; nesse atravessamento, contudo, a distância segunda, aquela alcançada após vencida a do teórico, já não é igual à primeira. Isso porque a aproximação permitiu pôr em causa o sujeito que se implicou nesse processo, impossibilitado agora de possuir ou de dominar o objeto particular a que se dirige, de ter sobre ele alguma garantia, passando, então, a ser tocado por ele. Desse encontro, desse vai-e-vem, dessa fricção com esse objeto particular, decorre a distância segunda, que nada mais é, afinal, do que aquilo que se escreve, que se testemunha, desde que permitamos e toleremos a transformação que, no corpo do texto mesmo, o texto do leitor, isso opera. Nesse momento, e não antes, convocar a vastidão de um repertório literário, filosófico e mesmo científico colabora se, e apenas se, conduzir "a leitura a uma maior complexidade" e contribuir "para desenvolver mais intensamente a sua liberdade criadora" 4 (liberdade essa tão oposta aos resumos, fichamentos e esquemas escolares ${ }^{49}$ ); isto é, todo nosso saber é convocado aqui, por assim dizer, a posteriori, a fim de lançá-lo para fora de si, rompendo-lhe os cercos e abrindo-se à potência poemática.

O pensamento não se confunde com a filosofia - distinção de origem heideggeriana ${ }^{50}$-, embora não a precise excluir. Ele a excede. Não só a literatura mas as artes como um todo funcionam, desse modo, como um a mais do logocentrismo filosófico, uma vez que produzem sentido "sem pertencer à ordem do sentido", ${ }^{11}$ questionando o próprio discurso da filosofia e relançando uma outra modalidade do pensar, capaz de introduzir "as descontinuidades pelas quais o mundo pode recomeçar" ${ }^{52} \mathrm{O}$ criado torna-se, pois, "portador de algo que não pode ser controlado pela filosofia”, guardando, em si uma autointerpretação das tradições, no momento em que as rompe. "O que chamo de pensamento é um gesto polêmico com respeito às interpretações correntes [...]", ${ }^{53}$ afirma Derrida, ressaltando que algo na obra se pensa, na experiência da obra e incorporado a ela. Somos, portanto, pensados por ela. Nesse sentido, o pesquisador de literatura tem, como tarefa, também ele, "transbordar o discurso regular da pesquisa" .

Como "regime discursivo de exceção", ${ }^{55}$ a obra literária é ilimitada e não pode servir a uma via única de sentido, insubordinando-se, assim, aos fins e à sua instrumentalização. Por isso, não convoquemos aqui um elogio (prescrição) à leitura a qualquer custo, cuja banalidade pode, inclusive, surtir um efeito contrário e não raro destinar-se a destacar a suposta importância da quantidade de obras lidas. O que deve importar não é conhecer uma dada quantidade de textos e teorias, mas as "intensidades dos dinamismos" em um texto, "de onde decorre a multiplicação das leituras, as relações entre leitura e escrita, o desencadear de problemáticas" ${ }^{56}$

Pensar a obra menos como "ser estável" (o que significaria reforçar-lhe os estereótipos) e mais como acontecimento
51. DERRIDA. Pensar em não ver: escritos sobre a arte do visível (1979-2004), p. 46.

52. LOPES. Poesia e ideologia. In: Literatura, defesa do atrito, p. 71

53. DERRIDA. Pensar em não ver: escritos sobre a arte do visível (1979-2004), p. 47.

54. BARTHES. Jovens Pesquisadores. In: O rumor da língua, p. 101.

55. LOPES. A paradoxalidade do ensino da literatura. In: Literatura, defesa do atrito, p. 95.

56. LOPES. A paradoxalidade do ensino da literatura. In: Literatura, defesa do atrito, p. 99.

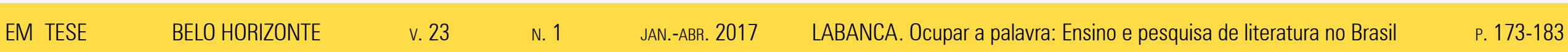


57. LOPES. A literatura como experiência. In: Literatura, defes do atrito, p. 32.

58. PESSANHA. Equação natal: presença roubada. In: Instabilidade perpétua, p. 33.

59. LOPES. Do ensaio como pensamento experimental. In: Literatura, defesa do atrito, p. 128.

60. LOPES. A paradoxalidade do ensino da literatura. In: Literatura defesa do atrito, p. 94 significa pensar aquilo que nela é heterogêneo ao conhecimento. A enunciação-acontecimento reinstaura a contingência "enquanto decurso do tempo na sua não-linearidade", ${ }^{57}$ que nada mais pede de uma estratégia ou de um aparato de análise preexistente. Dessa enunciação, a leitura pode participar de outro modo: respeitando o inacabamento que lhe é próprio, redobrando-lhe a complexidade e a excepcionalidade desse dizer que também mostra, calando-se, por vezes. É preciso sustentar "o brilho do acontecer" ${ }^{58}$ diria sobre isso Juliano Pessanha. Abrir-se às reverberações, estimular um "pensamento que se ensaia, um pensamento por tentativas, que não teme o fracasso da totalidade" ${ }^{\prime 9}$ é tomar o texto como agenciamento de multiplicidades, incluindo perspectivas contraditórias, o que, por sua vez, pode suscitar o pensamento sem determiná-lo.

A convivência de paradoxos e o complexo uso da linguagem da poesia, da literatura, abalam a estabilidade do nosso sistema simbólico. Para além da comunicação a todo custo e das práticas pedagogizantes, propõe-se aqui assumir a responsabilidade de introduzir questões éticas e políticas mais profundas nas instituições de ensino, exercitando "o pensamento para a complexidade”. ${ }^{60}$ Para Derrida, o não saber é, inclusive, condição para o acontecimento, cuja responsabilidade precisa ser assumida - por professores, leitores e pesquisadores de literatura. Trata-se de suspender as respostas e permitir que cada um levante suas perguntas, inventando, para a literatura, um lugar mais desmobilizado - "além da normalidade e da exclusão"61 -; redoar, no mundo contemporâneo, um lugar - que se deve instaurar a cada vez -, onde sejam possíveis os afetos, contágios, riscos; um lugar, sobretudo, onde seja possível escrever, essa talvez seja a nossa tarefa mais premente.

Acredito que seja sempre necessário levar a análise às condições históricas, políticas, econômicas e ideológicas, levar a análise o mais longe possível, incluindo a história da forma de arte específica. Mas se a análise de todas essas condições for exaustiva, ao ponto de que a obra esteja ali apenas para preencher um buraco, não há obra. [...] Se há obra, isso significa que a análise de todas as condições serviram apenas para, como eu poderia dizer?, deixar o lugar [laisser la place], um lugar absolutamente indeterminado, para alguma coisa que é, ao mesmo tempo, inútil, suplementar, e finalmente irredutível a essas condições. ${ }^{62}$

\section{REFERÊNCIAS}

ANDRADE, Paulo Fonseca "Tenho um desejo imenso de altera a comunidade que vivo": Literatura, política e escola segundo Bartolomeu Campos de Queirós. Belo Horizonte, Faculdade de Letras da UFMG, abr. 2016. Conferência apresentada no II Seminário de Estudos Literários da UFMG: Pensar a Literatura Incomparável.
61. PESSANHA. Equação natal: presença roubada. In: Instabilidade perpétua, p. 40.
EM TESE
BELO HORIZONTE
v. 23
N. 1
JAN.-ABR. 2017
LABANCA. Ocupar a palavra: Ensino e pesquisa de literatura no Brasil
P. $173-183$

62. DERRIDA. Pensar em não ver: escritos sobre a arte do visivel (1979-2004), p. 53.

\section{Teoria da literatura e Ensino de literatura}


BARTHES, Roland. O rumor da língua. São Paulo: Martins Fontes, 2012.

BLANCHOT, Maurice. 0 espaço literário. Rio de Janeiro: Rocco, 2011

BRANCO, Lucia Castello; OLIVEIRA, José Marcos; et al. Práticas da letra. In: Nina Virgínia de Araújo Leite; J. Guillermo Milán-

Ramos; Maria Rita Salzano Moraes (Org.). De um discurso sem palavras. Campinas: Mercado de Letras, 2012, v. 1, p. 361-381.

DERRIDA, Jacques. Pensar em não ver: escritos sobre a arte do visível (1979-2004). Florianópolis: Ed. da UFSC, 2012.

HEIDEGGER, Martin. O fim da filosofia e a tarefa do pensamento. In: Conferências e escritos filosóficos. São Paulo: Nova Cultural 1999.

HOUAISS, Antônio; VILLAR, Mauro de Salles. Grande dicionário Houaiss da língua portuguesa. Instituto António Houaiss, 2012. Douaiss da língua portuguesa. Instituto António Houaiss, 2012 2017

LABANCA, Maraíza. a mais: palavra súbita, cheia de sargaços ou afetiva. Faculdade de Letras da UFMG, maio de 2016. Apresentação oral. Disponível em: <https://fiodeaguadotexto.wordpress. com/2016/05/15/estetico-convivio-20/> . Acesso em fev. 2017.

LEBARD, Joséphine. A l'école des futurs écrivains.

Le monde. Jan. 2017. Disponível em: <http://www.

lemonde.fr/campus/article/2017/01/27/a-l-ecole-des-futurs-

ecrivains 5069843 4401467.html\#KyyACCh6MZoz1WST.99 >

Acesso em jan. 2017.
LOPES, Silvina Rodrigues. Literatura, defesa do atrito. Belo Horizonte: Chão da Feira, 2012

PELBART, Peter Pál. Carta aberta aos secundaristas. São Paulo: n-1 edições, 2016

PESSANHA, Juliano Garcia. Como fracassar em Literatura. Pausa Belo Horizonte, n. 100, jun. 2013.

PESSANHA, Juliano Garcia. Instabilidade perpétua. São Paulo: Ateliê Editorial, 2009.

RAMOS, Nuno. Nuno Ramos. Jornal Rascunho. Entrevista

concedida a Paiol Literário em nov. 2011. Disponível em: <http:// rascunho.gazetadopovo.com.br/Nuno-ramos/>. Acesso em fev. 2015.

RAMOS, Nuno. Ó. São Paulo: Iluminuras, 2008.

REYES, Yolanda. Ler e brincar, tecer e cantar. In: Literatura, escrita e educação. São Paulo: Pulo do Gato, 2012 